Open Access

\title{
Intergenerational emotion and solidarity in transitional China: comparisons of two kinds of "ken lao" families in Shanghai
}

Wenrong Liu(i)

\author{
Correspondence: Iwr@sass.org.cn \\ Institute of Sociology, Shanghai \\ Academy of Social Sciences, 7/622 \\ Huaihai Road (M.), Shanghai, China
}

\begin{abstract}
The phenomenon of ken lao embodies the structural tension and intergenerational ambivalence in transitional Chinese families. Two kinds of families in Shanghai that rely on parents are compared, including attitudes, response strategy to ken lao, and the impact on the intergenerational relationship. In order to discuss the coexistence of conventionality and modernity in today's Chinese family life, the interaction and tension among the pursuit of material goods, values, and affect are analyzed. The findings of this research suggest that the reflexive change in urban families has not resulted in familial individualization. On the contrary, the ethics of intergenerational responsibility have been reconfigured in individual reflexivity and negotiated practices. The emotional structure of parent-child unity is strengthened in the transitional society, which contributes to the strong cultural resilience of the tradition of intergenerational cooperation.
\end{abstract}

Keywords: Intergenerational solidarity, Individualization, Ambivalence, Ken lao, Parent-child unity

In this paper, the term "ken lao" ${ }^{1}$ refers to the phenomenon that adult children are highly dependent on their parents on a daily basis, including both economic and labor dependence. Ken lao is a consistently important topic because of its double mismatch in culture. It is neither in line with the role of expectations in Chinese family culture under the feedback model (Fei 1983), nor in line with the Western individualistic cultural tradition of the self-determined individual (Yan 2006, 2011, 2012). This close relationship between the three generations is called "Chinese-style ken lao" and "postmodern ken lao" (Potu 2015) and presents an interesting reflection of unique Chinese familial intergenerational relations in the process of modernization.

Individualization is one of the characteristics of social transformation in China. China lacks classical individualism, and at the same time, state management and public welfare systems are also underdeveloped. Nevertheless, today's Chinese individuals live in a postmodern environment composed of turbulent labor markets, mobile occupations, growing personal risk, and an emphasis on a culture of intimacy and selfexpression (Yan 2012). In a certain sense, ken lao is the product of this particular individualized social context, a representation of the structural tension and ambivalence in the family domain of Chinese people. On the one hand, the high cost of living in modern society requires expenses to be shared by two generations, and young couples have

(c) The Author(s). 2017 Open Access This article is distributed under the terms of the Creative Commons Attribution 4.0 International License (http://creativecommons.org/licenses/by/4.0/), which permits unrestricted use, distribution, and reproduction in any medium, provided you give appropriate credit to the original author(s) and the source, provide a link to the Creative Commons license, and indicate if changes were made. 
a greater dependence on their parents for economics, housing, child care, and household chores (Song and Qi 2011; Chen 2012; Xu 2013). Reliance on the family has become more crucial for individual survival. On the other hand, the spread of individualistic cultural ideas makes the ideals of freedom and self-realization more prevalent and stronger for the younger generation than the older generation (Yan 2011). The inherent conflicts in the parent-child relationship and the intergenerational barrier have become more intense (Fei 2002).

This paper regards ken lao as a structured ambivalence of coexistence and conflict, aiming to understand how the traditional (ethics and norms of intergenerational responsibility) and the modern (individual rationality and emotional orientation) together shape current family life in Chinese cities. From the perspective of individualization and intergenerational ambivalence, this paper utilizes case studies from Shanghai to analyze two kinds of ken lao families - the harmonious and the conflicting - and their cognitive strategies and influence on intergenerational relations. It presents the interactions and tensions among family members in their interests, values, and emotions to discuss the question of how intergenerational solidarity can be achieved. This paper demonstrates that the emotions and responsibility based on blood relationships in intergenerational relations are still the basis of family identity in China's current social transformation. Individual reflexivity does not lead to the individuation of the family, but regenerates the ethics and unity of intergenerational responsibility.

\section{The intergenerational relationship in the process of individualization}

Beck and others' individualization theory argues that postindustrial times brought about new institutional demands, and the labor market requires greater autonomy, flexibility, and mobility. The second modernity freed the individual from the obligation of family unity, and family became a "selective relationship" in a demand unity (Beck and Beck-Gernsheim 2011, 110). In this framework, reflexive change has become the most important feature of a family in postmodern society. In the first modernity, familial relationships are prefixed, and family lifestyles and behaviors are constrained by social norms. However, under the second modernity, family life becomes a self-created cause of self-identity. Individuals are more concerned with the realization of expressive needs, and norms are no longer preceded by individual behavior but are constantly defined and changed by individual actions (Cherlin 2008). The theoretical framework of individualization has been effectively applied in explaining the rising divorce rate, staying single, late marriage, and choosing not to have children, but the explanatory power in intergenerational relations has been challenged. Gilding argues that the sociology of the family has turned to the paradigm of private-life research, but the overemphasis on reflexivity, institutionalization, and traditionalism ignores the biological basis and economic foundations of human behavior (Gilding 2010). Gilding's warning is equally applicable to the study of intergenerational family relations in China.

\section{Gaps in intergenerational relationship research}

Existing research on the process of modernization of Chinese families' intergenerational relations can be summarized into two paradigms. On the one hand, a large number of quantitative studies have shown that Chinese families still maintain a 
close intergenerational solidarity in the process of modernization. Demographers using census data have found that the proportion of three-generation households remained stable in China over the past 30 years (Wang 2014). Most studies based on survey data suggest that the intergenerational support relationship still follows the feedback model and that there are still close interactions between adult children and parents in daily care, economic support, and emotional comfort (Yang and Li 2009; Xu 2011). The concept of filial piety that has loving treatment of parents as the core is still highly affirmed among the young generation (Liu 2012). Although researchers agree on the coexistence of modernity and traditionalism in the process of Chinese familial change (Tang and Chen 2012; Yang and He 2014; Liu 2013), this research paradigm does not reveal how this coexistence is achieved, due to the constraints of the theory of modernity and the data. It reveals very little of the complexity of family life practice, new phenomena, and features.

On the other hand, some case-based studies focus more on the diversification of family structure, mobility, and strategic construction based on individual interests. They analyze revealing contradictions, pressures, and inequality in structures when studying intergenerational relationships. Under the revelation of individualization theory, some scholars have demonstrated the individual tendency of intergenerational relations in families. For example, there are studies that show that the rights of the offspring become more salient and stress the balance of personal interests and family interests (Kang 2012). Other studies focus on the loosening of the traditional institutionalized power structure of the family and the active construction of emotional intimacy (Zhong and He 2014; Xiao 2014; Zhang 2015). Some researchers have made a clear proposition regarding the individualization of Chinese families. For example, through the observation and analysis of the "temporary stem family," Yao (2012) finds that the current Chinese family has embarked on an evolution toward the "self-centered family." Based on the life experience and observations of Shanghai family, Shen (2013) puts forward the concept of the "individual family," emphasizing that individuals are self-centered and build the family structure and family relations according to their own needs. This kind of research follows the theory of individualization. In contemporary China, it is no longer the case that individuals live for the continuation of the family or family needs; instead, the family is constantly changing to serve the needs of the individual. Traditions as cultural norms have long lost their power of constraint; they are only resources available for the individual to use and serve as the "imagination of the community" to help in shaping the identity of the individual (Yan 2011).

The application of individualization theory in family research shows the agency of family members in the practices of daily life. However, current research makes it difficult to integrate the fact that the Chinese family tends to maintain intergenerational solidarity by emphasizing the competition over resources and strategizing the power among family members. For example, the perspective of individualization argues that when the parental generation volunteers in order to make peace between the generations, they face giving up their agency, transferring and losing power. The implicit logic of this conclusion is that the interests of family members are not consistent with each other's demands, and the relationship between personal interests and family interests is separate and competing. The understanding of the relationship between individuals and the family under the paradigm of individualization presents a barrier to the cognitive 
and emotional emphasis on relationships among Chinese people (Hsu 1990; Liang 2010; Pan 2000). Additionally, there is one question regarding individualization of the family--that is difficult to answer: are there still family interests that have a higher priority than the individual's interests? Many scholars think that the close intergenerational relationships in today's China are due to a basis of common interests and values (Yang and He 2014; Wang 2014). Thus, more nuanced research is needed to explore the impact of the structural forces from social transformation on individual behaviors, the emphasis of individual interests in the realm of values, the growing demand for intimate emotions, and how the conflict of individualistic culture and familial culture shape the daily life of the Chinese people.

\section{Intergenerational solidarity in the context of individualization}

Intergenerational solidarity is a multidimensional concept that includes both physical relationships such as encounters, and economic and labor help. It also includes nonphysical relationships such as the emotional and spiritual sense of belonging and intimacy (Cherlin 2008). When the term "solidarity" is used to describe the relationship among family members, it usually conveys the idea that the family is a whole rather than a group of combined individuals in addition to the idea that family members help each other. The behavior of the family is the behavior of the entire family rather than the behavior of one member toward another member (Bawin-Legros and Stassen 2002). Early researchers distinguished between the intergenerational solidarity mechanism of traditional society and the modern society. The former depends on the cultural norms of the family, while the latter depends on the emotional connection among the individuals (Burgess and Locke 1945). Bengtson et al. later refined the types of intergenerational solidarity: social solidarity, functional solidarity, structural solidarity, emotional solidarity, consistent solidarity, and normative solidarity (Bengtson and Roberts 1991). International comparative studies show that intergenerational emotional solidarity and instrumental solidarity were not correlated and even showed a negative relation (Silverstein et al. 2010). Although this independent division of typology can effectively explain intergenerational relations under different cultures, it cannot describe the process of intergenerational interactions in life practice. For intergenerational interactions in everyday life, normative unity and emotional unity are not isolated from each other but present an interactional and embedding process.

At the end of the twentieth century, intergenerational solidarity again became the focus of research. Differing from sociologists' emphasis on the mechanism of the social division of labor on social solidarity at the end of the nineteenth century, this time the background is mainly the second modernity of individualization, i.e., the loss of the effectiveness of "modern" social institutions such as marriage and community (Komter and Vollebergh 2002). Beginning in the twenty-first century, the importance of intergenerational relations increased tremendously and was viewed as the most important trend and hypothesis after the core family, the decline of institutions, and heterogeneous growth (Bengtson 2001). The intergenerational relationship between adult children and their parents in the postmodern economic and cultural environment of globalization, individualization, and privatization of welfare showed strong strength and elasticity, leading Western scholars to reflect on the historical limitations of the family 
as a concept (Swartz 2009). In reviewing William J. Goode's theory of family modernization, Cherlin points out that the changes in families around the world proved modern convergence theory and development paradigms wrong. Although the institution of marriage presents a clear developmental path of institutionalized marriage-companionate marriage--individualized marriage, viewing the family as a whole system, current families are going beyond the conjugal family mode and experiencing a return to complexity. Looking at Western society as a whole, marriage occupied the absolute dominant position in the family life only in the mid-twentieth century. Before and after that time, the family model was not like that (Cherlin 2012).

For the "expanded family" signified by a vertical axis in China (Fei 2002), we cannot even find a clear historical stage when the couple axis overweighed the parental axis. In the current situation of the compression of modernity (Chang 2010), individuals have not yet been completely liberated from the premodern tradition of filial piety and are already deeply embedded in the intergenerational relationship under the postmodern style of risky social situations. It needs to be pointed out that the growth of solidarity is not equivalent to the reduction of conflicts. On the contrary, in the risk society categorized by cultural diversity, diminishing of absolute authority, marketization of the economy, and globalization, family members experience an increase of conflicts in interests and values.

\section{The reflexive characteristic of intergenerational relations}

The individualization theory argues that reflexivity goes beyond customs and norms in the postindustrial era. The criteria for individual action depend on the consequences of prior decision-making and the quality of actions rather than the established rules and historical traditions (Gilding 2010). Individuals dissociate from the traditional family system and kinship. A linear standardized life trajectory no longer exists. The liberated individuals have to live for themselves, looking for the bases of their own behavior and making decisions through various attempts and efforts, including cohabitation, marriage, divorce, and remarriage, putting together their own life trajectory (Beck and Beck-Gernsheim 2011). The study of low-income groups shows that in the individual's reflexive life, the production and maintenance of family relationships depend on the individual's emotional experience and identity. This emotion arises from common life experiences and instrumental support as well as sharing of values (Gazso and McDaniel 2015). Observations of intergenerational relations in China also find that instrumental support and emotional support are not a binary, two-part relation (Zhong and He 2014).

This paper therefore argues that the intergenerational relationship in life practice is reflected in the process of continuous consultation between family members according to their respective interests, values, and emotions. First, the basis of the change in the intergenerational relationship is to meet the daily needs of family members and the response to illness and death. This type of mutual assistance and collaboration makes up the identity of "home is home" for family members. The impact of social transformation on family intergenerational relations does not directly change the expectations of the two generations on solidarity, but the complexity of the external environment of the family exacerbates the dilemma of balancing the needs of the two generations. Second, the intergenerational relationship involves the process of interacting and 
constructing family members' cognition, ideas, and emotions. Moreover, the long-term, patterned interaction among family members precipitates the emotional structure of the individual, affecting specific individual decisions. Third, the standards of individual actions are selective, but cultural norms and traditions are not unimportant. Rather, they are presented as a subjective structure that is inherent in the "heart" (Zhou 2004) and have an impact on individual behaviors as well as the ideal of family life and the expectations of intergenerational relationships.

In the study of Chinese families, the emotional structure is a "neglected and important research subject" (Fei 2002, 149). In recent years, researchers have begun to pay attention to the significance of emotional ties for intergenerational solidarity. Some researchers find that the parental generation takes the initiative to offer economic resources and labor resources, and even gives up the power to compete in order to construct an intimate relationship with the offspring. The findings say that parents "being chewed" by the children do not signify their losing in the game of power with the children, but is an indication of the rising importance of building reciprocity between the parents and the children (Zhong and He 2014; Xiao 2014; Zhang 2015). Analyzing the existing studies on intergenerational relations shows that studies focusing on the younger generation emphasize the rational logic of the actors, and parent-centered research highlights the emotional logic of the actors. In fact, to properly theorize what is happening in real life, the emotional orientation of the offspring and the rational action of the parents cannot be ignored. Intergenerational ambivalence may be a useful theory in understanding the internal tension of the family in the changing society.

\section{Ken lao from the perspective of intergenerational ambivalence}

The concept of ambivalence from the psychoanalytic school refers to the coexisting and mixed state of positive and negative emotions. The sociological sense of ambivalence mainly refers to contradictory emotions, attitudes, and behaviors as well as contradictions between structural resource constraints and the actual demand, cause by incompatible role (status) responsibilities or expectations (Connidis 2015). From the macro perspective, ambivalence arises because the social norms of the parent-child relationship itself have conflicts. From the micro perspective, the interdependence within the family, intergenerational inequality of instrumental support, and incompatible values between the parents and the children can all give rise to ambivalence (Fingerman et al. 2013). Studies find that when adult children rely on their parents financially, the parents have a sense of ambitendency. On the one hand, parents feel that they have the responsibility to help and provide instrumental financial support for their children, based on the ethics of responsibility. However, at the same time, they feel that adult children should independently establish their own life, and even believe that the children should provide them with instrumental support (Pillemer and Suitor 2002).

Ken lao is an obvious ambivalence between solidarity and conflict in the intergenerational relationship. On the one hand, the ken lao family achieves close mutual support between the two generations, especially from the parents to the children. It eases social pressure and anomie caused by the rapid social transition. However, the instrumental solidarity of the ken lao family does not necessarily bring about harmony and emotional solidarity in intergenerational relations because adult children's high dependence on their parents is neither in line with the modern sense of individualistic culture nor does 
it conform to the traditional sense of filial piety. Research shows that when actors deviate from institutionalized norms and family lifestyle, they cannot fulfill a family role that meets social and cultural expectations. Family members experience feelings of being torn and anxiety from mixed positive and negative emotions (Fingerman et al. 2013). From the perspective of intergenerational conflict, the psychological and mental cost of devotion essentially reflects the contradictory characteristic of the relationship and structure (Connidis 2015). Shi (2014) argues that Chinese people are influenced by individualization processes and structural constraints. Individuals in a particular intergenerational relationship vacillate between independence and responsibility. Whether the intergenerational relationship ultimately moves into solidarity, conflict, or disintegration depends on the consultation and strategy between the individual and the structure, and in the different behavioral strategies when dealing with these contradictory emotions.

In China, ken lao is an interesting phenomenon because of society's flexibility in accepting it. There is a long tradition for Chinese parents and adult children to have a close relationship that involves mutual support and reciprocity. Intergenerational dependence is a symbol of happiness, although many researchers believe ken lao is reverse feeding (Che 1990) and "intergenerational imbalance" (Liu 2005; He 2009). The phenomenon highlights young people's self-interest, and is a result of them ignoring the parental benefits. The young people are criticized as "uncivil individuals" who display "self-centered individualism" (Yan 2006; Zhuang \& Jian 2013). However, in real life, it is not uncommon that parents are willing to be relied on (Geng 2010).

What kinds of ken lao are acceptable in practice and which are unacceptable? In the focus group for this research, two criteria for parental judgment were used. The first was whether children's dependency went beyond what the parents could afford. If the parents were in good financial standing and good physical condition, then caring for the children by contributing money, cooking, and taking care of household chores is acceptable. However, if the parents are not in good shape, then such children are viewed as abusive. A second criterion is whether the children show filial piety and appreciation. If the children showed signs of feeling apologetic and awareness of their parents' sacrifices, then this devotion is "nothing" and "understandable." Otherwise, it is the conduct of an "evil child" or a "debt collector." This information demonstrates that whether ken lao is successfully rationalized depends both on the objective resources owned by the family and the subjective understanding of family members and ultimately embodies the degree of emotional integration.

\section{Data collection and case summary}

In the everyday context of China, ken lao is a vague and controversial concept that goes far beyond "NEET" (not currently engaged in employment, education or training) in the English context, meaning that individuals have the ability but do not work, go to school, or receive training. Existing studies base on their judgment on the cultural norms of the feedback model, that is, adult children in intergenerational support relations should play the role of the giver rather than receiver (Song and Qi 2011). Based on the way of and instrumental resources for children's reliance on their parents, different scholars have categorized the behaviors into "explicit ken lao", "hidden ken lao", "active ken lao", "passive ken laon", "reliance on money", "reliance on labor services", and "reliance on relationship" (Ma 2008; Fei 2009; 
Jiang 2012), as well as other types. From the heterogeneous definition and classifications, we can see that the core of ken lao is that adult children are highly dependent on their parents, but the boundary and connotation are very flexible.

In order to reflect the various forms of child dependency in reality, this paper takes a broad stance to define the ken lao group as having the ability to work, graduated from school, currently unemployed or employed, obtaining income, but still relying on parents on a long-term basis to provide extensive support and help, including financial support and labor support. This study selects harmonious and conflicting ken lao families for comparative analysis from the cases pool, based on the criteria of acceptability.

${ }^{2}$ In the specific selection process, two main criteria were used. First, the subjective attitude of the interviewed family; that is, the parents or children or both believe that the children are ken lao. Second, the daily life of the offspring is highly dependent. The children in these cases state that living alone without help from their parents is impossible, and they hope this help will continue. The cases were drawn from relatives, friends, or neighbors, or introduced by friends from the author's network. In addition to the availability, the final selection of the cases took into account the comparability of the types of ken lao and intergenerational relationships, as well as the differences in gender, age, and family background of the respondents.

Of the four families included in the study, nine family members were interviewed. I interviewed both the parents and daughter in one family, and for the other three families, I only interviewed one of the parents and the children. Cases 1 and 2 were intergenerationally harmonious families, cases 3 and 4 were conflicting families, and cases 1 and 3 were mainly financial dependency. While cases 2 and 4 also had financial dependency, the labor dependency was more prominent. One official interview was held with each family, among multiple informal interviews and observations. Because the closeness of the relationship with the author was different for each respondent, the number of observations and interviews also differed. The interviews were conducted in a semi-structured way. Through interviews, I listened to their stories, understood how their families formed ken lao, discussed the views of the two generations on issues related to ken lao, and their understanding of intergenerational relationships.

\section{The harmonious ken lao family}

Case 1: Offspring T, male, 32 years old, college graduate, unemployed, married with a 4-year-old child. His mother was 58 years old and a hospital doctor; his father was 59 years old and a university professor.

After graduation, T's work did not go smoothly. It has been 10 years since he quit his job; he has not worked since. The family is affluent; they own a car and an apartment. Currently Mr. $\mathrm{T}$ and his wife take care of their child and parents on both sides in exchange for stipends from both sets of parents.

Case 2: Offspring $\mathrm{X}$, female, 37 years old, doctoral degree, college faculty, has two sons, a 6-year-old and a one-and-a-half-year-old. Mother, 62 years old; father, 69 years old, both retired.

At the beginning of X's pregnancy, her parents moved from their hometown to their daughter's place to help the daughter and son-in-law with household chores and childcare. Since the birth of the third generation, the grandmother has taken care of the 
grandchildren, overseeing their sleeping, eating, dressing, getting vaccinated, and seeing doctors for 6 years. In addition, the parents have supported her daughter twice in realestate purchases. The first time, they helped her pay the down payment, and the second time, they sold their house back in their hometown.

\section{The conflicting ken lao family}

Case 3: Offspring Y, male, 26 years old, graduated from the Academy of Fine Arts, professional oil-painting artist. Mother, 56 years old, accountant, widowed.

Y gave up a stable job as a schoolteacher after graduating, hoping to become a known name in oil painting. He does not have a stable job. His paintings sell poorly. He mainly relies on his mother for financial support.

Case 4: Offspring L, female, 43 years old, master's degree, divorced, single mother with a 2-year-old. Father, 74 years old; mother, 69 years old, both retired.

$\mathrm{L}$ divorced twice. Her child was born just after the second divorce. Because the daughter needed to work, the parents came to live with her to help her with childcare, cooking, and household chores. L's father also helps her with her stock investments.

\section{Case analyses and findings}

The continuously changing elements in ambivalent intergenerational relations include the forces of both push and pull. The outcome of intergenerational relationships may be characterized by solidarity, conflict, or ongoing ambivalence, depending on the continuous negotiation when individuals attempt to meet their own, their family, and society's contradictory demands and expectations (Connidis and McMullin 2002). Rationalization and acceptance are important strategies for individuals to deal with intergenerational ambivalence (Spitze \& Gallant 2004). The degree of recognition of the intergenerational responsibility undertaken by the actors and the expectation of intergenerational relations both affect the possibility of rationalization (Connidis 2015). Only when the offspring and the parents rationalize ken lao will intergenerational relations maintain balance and harmony. Otherwise intergenerational relations will be imbalanced due to tensions.

\section{The harmonious ken lao family: rational cooperation across generations}

In the harmonious ken lao family, the two generations achieve intergenerational reciprocity and emotional solidarity on the basis of consistent interests and values. Although ken lao seems to solely benefit the younger generation, the core of ken lao is a continuation of parental authority and ethics of responsibility. However, different from the traditional authoritarian relationship, intergenerational interactions are presented as an intimate form of equality and care.

\section{Emotional cognitive understanding and acceptance}

First, the two generations attribute the ken lao situation to each other's care and love. These family members often used the phrases "From the interests of the other side" and "consider each other's feelings and needs" to describe the most important factors. For example, in Mr. T's (case 1), his parents worried about his "body collapsing", so they allowed him to quit his job to stay home and recuperate. Later, they worried that their son would "learn bad things from the outside" and "embark on a crooked life style," and preferred to support their son, so that their son is living under their 
observation. During the interview, T's mother did not express the traditional expectations of Chinese family culture for the young to "make the ancestors proud," nor the Western individualistic cultural expectation of an independent self. Instead, the parents emphasized the values of family harmony, health and fitness and emotional companionship.

Initially our child was going to work upon graduating. It was still a probation period. Work was far away and it took one hour in the subway just one way. In the two months he worked overtime for thirty days, and sometimes even all-nighters. ... Two months later he was sick! It was too much for the body ... Our child was not very healthy as a child. I am a doctor. I know it the best. If we let him work, his body would have collapsed. Everything was over then. [In the] IT industry [there are] too many cases of sudden death. ... In fact, we are not demanding. I do not need them to make a lot of money as long as they are healthy and happy. They are now a family of three and living with us. We are more than satisfied. (Case 1 interview record, mother)

Ms. X (case 2) has an advanced degree but is highly dependent on her parents. She even followed her mother's advice when deciding whether to have a second child. In her own words, "Our home is sustained without me and my husband, but the grandfather and grandmother are indispensable; without them our household cannot go on." In the view of some scholars, it is the parents' doting and their omnipresent behavior as an agent that hinder the normal socialization of their children, causing their children to lack the ability for basic self-care (Zhang 2010). However, the interview data shows that from the perspective of the family, it is this dependence that constructed their "mother-daughter filial piety," which led to the harmony of the family. It recreated the intergenerational responsibility of ethical behavior toward each other. In the interview X's mother fully expressed her intention "for the sake of the daughter." She is a fulltime, constantly worrying mother. Because the daughter "from childhood knew only how to study, and knew nothing about housework," if the old couple did not come to help she would "have to cry." The mother was not only worried about her daughter's physical health, but also that her daughter and son-in-law would have marital conflicts because of the division of labor. She worried that taking care of the children would damage her daughter's career because "women must work-no work, no status." She even worried that "one son is not dependable" and strongly persuaded her daughter to have another child.

The children emphasized their own sense of independence and responsibility, using such phrases as "for the parents", "filial piety", "self-sacrifice", and "responsibility" to shape their own moral image and to legitimize ken lao behaviors. For example, in the interview, Mr. T repeatedly stressed that his current ken lao state was actually a job, with his parents serving as his "boss." He has been working hard to repay them. Moreover, this was a "voluntary, harmonious negotiation, not a compulsory situation," characterized as a fair relationship rather than him taking advantage of the parents. He even stressed that taking care of their parents and children's living was "us (husband and wife) who sacrificed (the opportunity) to build a foundation in the society" in order to achieve a "win-win" situation for the family. This both saved costs for the family and 
provided companionship for the parents. Ms. X said that she was very grateful to her parents for their help when she talked about her long-term dependency on their doing the housework, but at the same time, she believed she was capable of doing housework and was a "person who could handle things." The current ken lao situation arose more out of accommodating her mother's "tendency to worry," stating, "Since she has done everything, I cannot worry about those things anymore; the more people, the more conflicts," and "When she [the mother] is not happy, we are all not happy," suggesting that this is the daughter's effort to achieve family harmony.

In addition, it can be observed that there is a high degree of recognition and acceptance between the two generations. On the one hand, the parents do not identify the child's ken lao behavior as a child lacking independence or their failure in life, but have a positive understanding of their children's behavior. In the interview with case 1, T's mother said that by the seventh or eighth month of her son, acting as a "nanny" at home worried her since she believed that "a dignified big man never working is not a proper thing." However, after her husband, a "quite insightful" professor, discussed the situation, her anxiety gradually decreased, and she recognized that her son's willingness to stay home implied that he was a "boy of patience" and "it is a good thing." T's mother did not read the fact that her son was not working as the child failing at socialization, and even viewed the fact that her son was also "persuading the in-laws to give them a stipend" as "the child is so capable." Her words were full of understanding and praise of her son.

Parents often described their children as "obedient" and "sensible." For example, T's mother thought that her son's initiative in taking care of a young child and the older generation was an indication that her son "knew that he (was) a grown-up now" and felt "bad about living and eating without paying"; this was "his good trait." Because of the parents' recognition and care as well as enjoying a high degree of autonomy while growing up, the offspring almost never thought about separating from the parents and never seriously considered the meaning of "independence." Instead, they believe "My parents only have one child; isn't living together and engaging in mutual care just great?" (Mr. T), or "My parents will eventually want to live with me anyway; it's better to adjust to that earlier" (Ms. X).

\section{Rational construction of intergenerational reciprocity}

In the harmonious ken lao family, the two generations deem the current ken lao relationship as one of intergenerational reciprocity and cooperation, and a cost-effective, rational arrangement. This arrangement is a family-based, rational economic calculation. Each generation gets what they need from the ken lao relationship. For example, Mr. T and his wife in case 1 could "work for their parents" for 10 years because the two generations had rationally calculated a cost-benefit budget.

Both parents are very satisfied with the current situation. It can be said that they are extremely happy. ... In fact, many people never calculated their budget. If you did, you'd agree. I do not work, but I prepare two meals a day. How much money do you pay a part-time cook? Twenty-five yuan an hour and three hours a day? Seventy-five yuan; a month is 2,250 yuan, right? Purchasing daily necessities, buying food, you need manual labor for that, right? How much does it take to find someone to take 
care of a child? An advanced nanny may cost tens of thousands of yuan. Early education is to teach them all the knowledge they need before starting kindergarten! How much money would this be! Saving these expenses is earning money. We devoted our time and effort and saved tens of thousands of yuan of expenditures, much more cost-effective than if we went to a nine-to-five job and earned 5,000 yuan each, right? (Case 1 interview record, son)

During the interview, T's mother stated that because of their busy careers, she and her husband had no time to cook. "We changed several part-time workers and the ones we liked couldn't stay long enough." Her son just happened to like doing housework and having their own family to cook and care for the grandchildren allowed them to "rest assured" and gave them "peace of mind." Similarly, in case 2, the daughter in a family of four, living together also felt "assured" and had "peace of mind." X's mother said, they could spend "five or six thousand every month and they still would not find someone like me and her father, so dedicated, and can take care of all the work around the apartment." She pointed out, "Taking care of the grandchild is not just the general care [of] eating and sleeping, but also taking the grandchild to school, to see a doctor. It involves a lot of responsibilities." Since the domestic labor market and nanny services are not reliable and young parents have to go out to work for the family, asking the grandparents to take care of the grandchildren became a family strategy after a rational calculation by the two generations.

In addition to economic rationality, this reciprocal relationship also comes from the instrumental devotion of the parents in exchange for the emotional and spiritual return from the children and grandchildren. For example, T's mother emphasized that having the son's family of three "accompanying my side" meant they did not embark on a crooked path, fully demonstrating the emotional and spiritual dependence on the only child in the family. X's mother in case 2 not only received emotional feedback from the younger generation but also a sense of self-improvement. She believed that the family "did not experience any big conflicts in 6 years," mainly due to her sacrifice and dedication. "I've done everything there is to do, what else do they still need to do?" Moreover, she contributed to her family and was proud of the status she had within the family. "My son-in-law told his coworkers I am a big deal, and joked that I was an elementaryschool student managing a Ph.D. [daughter], a master [son-in-law], and an undergraduate [husband], and there are also two other little devils [grandsons]!"

\section{Consensus in interests and showcasing the intentions of the parents}

Harmonious ken lao family shows a distinctive integration of values in their intergenerational solidarity. First, the two generations have a common "big family" concept and symbiosis of interests. The two generations view the family of three generations as a whole. For the continuation and development of this three-generation family, family members undertake different divisions of labor at different times. X's mother in case 2 said, "We, the old, take care of the things inside the house, so that the young people have peace of mind to work. If they do well, it is also our accomplishment, isn't it?" In the symbiosis of interests and tacit understanding, the devotion to the younger generation is also devotion to their own future. As other studies have shown, the intergenerational relationship of one-child families is more equal, intergenerational emotional 
interaction is more frequent, and the spiritual communication is more intense (Liu 2013) than in families with more than one child. In this solidarity, not only does the parental generation willingly view the responsibilities of the children's generation as their own, the children also see protecting the interests of the family as their own responsibility. In the interview, cases 1 and 2 mentioned multiple times that "I am the only child of my parents," and the future of the parents "is always my responsibility."

Interview data from case 1 showed that the two generations reached a consensus over the future of the family, that is, after the parents' retirement, the couple would again work to make money, and the old couple would take care of the housework. Although finding a job in the future was "worrisome," for this family, someone is always needed to do the housework. Having the son stay home was a reasonable and the least risky arrangement for now. As T's mother put it, "Wait a few years after we retire at home with the grandchildren. The two of them can feel at ease in making something of their own. After all, when they are a little older it is not easy to go down a crooked path." In the interview, Mr. T also said, "When my parents retire, they can take care of the children, and great! We can rush out, both rushing into the world!" which showed confidence and longing to take on future responsibilities in the "outside world." For this family, the two generations' common picture of the future effectively diminished the anxiety and dissatisfaction of the parents regarding the status quo. It is inevitable that the parents will age and return to the family. When the offspring have a strong opinion of their own value, it greatly reduces their shame. Thus, in such a family, the younger generation does not consider themselves as failures because of their current dependence on their parents.

Moreover, the two generations also have a common emotional response and intergenerational awareness. In the "three-generations-as-one" value system, the third generation constitutes the ultimate interest of the family. It represents a person's farthest future that one can see alive, which is also the common future of the two generations. During the interview, Ms. X retold the negotiation process regarding the choice "to have a second child."

My husband initially absolutely opposed it. He said that having two children was not the life he wanted, and even said that having another one was going to destroy his life! The conflict is still quite significant. ... Indeed, the financial pressure and devotion of time to two children are quite costly ... but my mother kept trying to talk to us about it, that having only one child is not good for the child, we are going to die one day, and when it happens MM (referring to the eldest son) will have no one in this world to care about him. ... I am the only child and I was very touched. ... A key point is that my mother said that she would take care of the child; we do not need to worry about it. ... I said to my husband, there is such a strong supporting force, what is there to be afraid of? We listen to my mother's words; in fact, they are from the experience of so many years. ... A lot of things in our family are done according to her decisions because the general results also proved that nothing would go wrong. If the grandmother's decisions were always wrong, we would not listen to her. Right? (Case 2 interview record, daughter)

Existing research points out that the parental generation voluntarily transfers their power in order to maintain intergenerational intimacy with their children (Xiao 2014). The case in this paper shows that the offspring also maintains their mutual support 
and relationship by transferring their power. In the above case, the daughter stated that complying with the mother's will was their own "active" choice, stressing that her obedience was not blind to highlighting the rational and the autonomy of the self. However, her reason for relying on experience rather than individual reflection in fact came from her intuition that "mother is always right." Thus, in the harmonious singlechild family, the dependency of the offspring depends on deeply rooted trust and emotions. It is based on long-term successful protection and loving intergenerational interactions that give rise to the feeling of trust. It has become a natural and rational choice of the offspring to be obedient and follow parental authority. In addition, the above interview shows that apart from the rationality of the young, it also reflects the shared thinking and feeling of the two generations that "the third generation is the most important." The ideas of "for the children" and "let the children have someone in this world" successfully inspired the emotional identity of the children's generation and reduced the cost of intergenerational negotiations.

\section{The conflicting ken lao family: rational conflict under the emotional kidnapping}

In the conflicting ken lao family, the family fails to successfully rationalize the behavior of the children's generation. The main reason is the failure to integrate values, which leads to the failure of rationalization. Because of the differences between the rational choice of the parents and the children, the emotions and responsibilities formed by the parent and child loses the foundation of reciprocity and balance between the two generations, and the intergenerational relations have ambivalence due to the coexistence of intimacy and conflicts.

\section{Value conflicts and emotional kidnapping}

The interview data show that the two generations' understandings of the value of life have deep divergence. Inconsistent values, especially not identifying with the life choice made by the child, greatly damage the parent's willingness to be devoted to their child, and it also hurts the relationship between the generations. From the parents' view, the children "take the initiative" to not have a stable job, to not form a "complete" family, lack planning, and have no plans for the future. The characteristics of the ken lao clan are summarized by some scholars as "lacking clear self-awareness and positioning", "high in the heart" "but low in capability", "too idealistic", "self-centered", and "do not care about the feelings of the parents" (Zhang 2010). These ideas were repeatedly stated by the parental generation.

What are young people thinking about these days, I really do not understand! Good job opportunities, they give them up! Direction toward earning money, they give up! Just dreaming day and night; can anyone become the first something in China that easily! You are not born into a rich and affluent family. What are we? Working class! Living off this little dead money. What do you want to do with that? You look at other's children, even those who had low grades found a stable job, unlike the debt collection in my family dreaming all day long. (Case 3 interview record, mother)

I told her that if you intend to live alone for the rest of your life then just get a divorce! But who would imagine she would come up with such a thing [having a 
newborn and divorcing] without giving a heads up? People should have some awe in the heart. You never know what will happen in the future and should also plan for the long-term, have a plan B! (Case 4 interview record, father)

However, the interview data from the children's generation shows that they believe their choices in life came from self-confidence and the intention to have a more valuable life, although people of "my parents' generation cannot understand." Mr. Y (case 3) knew that copying paintings for others would allow him to provide for himself, but he said: "Once you start to commit to making a living by copying paintings, it is difficult to have your own creative inspirations. ... My greatest wish is to be the first in oil painting in modern China. ... Giving up the dream to copy paintings is a waste of my talents." The idealistic Y believed that his ken lao situation was only temporary. In the interview, he said, "I cannot really sell my own paintings to make my living, but later maybe I will be China's Picasso or Van Gogh.” As for his life and financial dependence on his mother, he felt that these were only temporary. When he became successful one day, all of his mother's devotion would reap returns. Ms. L (case 4) wanted to divorce before she had a child and did not want a "loveless life." The reason she waited to divorce until after she had a child was because she realized that she was getting older and her friends told her, "If you want a child, this may be the only chance." After two marriages, she was disappointed with marriage. She was eager to form a stable sense of security through blood ties. "In this era, people do not have high expectations for marriage. The couples just split up, but the relationship with the child is always stable. As long as you do not hate children, a child is always a good thing."

The interview data also reflects the parents' strong reluctance and the helpless feeling of being kidnapped by emotions. The mother in case 3 repeatedly talked about the hardships of raising her son alone, complaining, "If it was not for this little devil, my life would be so much more comfortable. ... I used to work as a factory worker. I worked three part-time jobs as a company accountant doing bookkeeping, tax returns every day without rest [in order] for him to complete college." She originally believed that when her son graduated from college, things would be better, but 3 years after graduation, she still had to earn money for her son to buy canvas, paints, and brushes. "My sisters were telling me that I'm too crazy about making money, and certainly saved a lot of money," but in fact, even the money for the future daughter-in-law was not properly saved. In case 4, L's mother reluctantly admitted, "Hiring a nanny to take care of the child also requires someone to be home during the day. If we do not come to live with her, how does she go to work? If she does not go to work, how can she raise a child?" L's father stated that living with his daughter is purely out of choice and entirely because "her mother wanted to help, and her health is not good, so I had to follow her." When talking about their present life, the parents of each family were full of complaints, repeatedly talking about their "hardships" and the child's "insensibility," and complaining about being dragged down by their children. These complaints toward their children and their children's stubbornness regarding the status quo created a long-term state of tension in the intergenerational relations.

\section{The ambivalence under responsibility ethics}

The major reason for the parental - generation's negative emotions is the dilemma between "unavoidable responsibility" and "having no choice". Interviews showed that 
the parents did not directly express recognition of traditional ethical norms, but viewed being "burdened by the children" and inability to "ignore the children" as having no choice. This parental responsibility is irrefutable. In case 3, Y's mother did not always support her son's choice, but felt she had to give him money for three years to support his independent creative career. Although she stated that she had given her son an ultimatum for a maximum of two more years, we can foresee that if the son insists on maintaining his lifestyle the mother will still be paying for her son in spite of her complaints. Other cases in this study also show that the parents will be forced to tolerate their children's ken lao. Their real concern is not that the child is using their money, because "being parents you give the best to the children; yours is theirs too" (add citation). Their deepest concerns center on how the child will live. In the case of $\mathrm{Y}$, his mother repeatedly mentioned, "When I am old and cannot move, and he is still like this, what can I do?" In case 4, L's deeply anxious father also felt he had "no other choice." He expressed his unwillingness to help his daughter with her children and financial management, not wanting to take on "this suffering", but on the other hand he also expressed the idea of feeling a responsibility to her "no matter what." "She typically uses bricks from one wall to fill another hole in the wall. She has too much debt and expects to earn money in the stock market. I know her financial management ability; if I do not help her she will soon lose everything. If that happens how can anyone fix it? I educated her, but she is just not obedient. Things are already like this; what can I do? She has no other way to go. ... I cannot look at my own child dying in this world, right?" (Case 4 interview record, father)

Yan Yunxiang points out that the main reason parents make concessions to their offspring comes from the emotional and moral aspects of a "parental heart" (2012, 218). Some scholars also point out that ken laos exist because the one-way protection provided by parents still constitutes psychological pressure (Zhang 2008). The case analysis of this paper also shows that parental concessions are not only the result of moral restraint but also a rational choice within the family's welfare ideology. In the interview, L's university-educated father expressed his concept of intergenerational responsibility: "Parents cannot cover for their children for a lifetime; eighteen years is the end of [our] responsibility." However, he also said that "it is impossible in reality!" He believed that his and his daughter's interests were indivisible. The future failure of children also indicated a failure for themselves that would not "end well." This sense of responsibility not only arises from human emotions but also reflects the inertia of Chinese people under the long-term family welfare system. Based on the parental view of bundled interests, unlimited liability, and parent-child unity, the "natural" reaction and way of thinking for parents is that children are the parents' responsibility.

Second, the ambivalent intentions of the offspring lie in the ingenuity of the instrumental dependence on the parents, and the emotional distance from the parents. During the interview, Mr. Y expressed a strong desire to pursue freedom. In explaining why he still spends money on renting an apartment although he earns little money, he said: "I am an adult, and I'm engaging in artistic creation. Of course I need a very independent space. Living with my mother I'll be bound in many ways and it will make me feel less free. My creative inspiration will be affected." The children's stubborn way of living stems from characteristic reasons, but it is also affected by the idea that "what 
my parents own is mine," and "what I have in the future will belong to my parents as well." This concept of parent-child integration justifies ken lao behavior. In only-child families, ken lao is even more justified. For example, in case 3, Y is confident about his future repayment of his mother's help, and this confidence stems not only from belief in his own talent but also from his identity as the only child. In a family-centered culture of parent-child integration, this only-child identity makes him almost unthinkingly claim that he is the only supporter of his mother's future life. That background is the potential contract and guarantee that he and his mother can maintain the status of ken lao.

\section{Rational conflict and failure of filial piety}

Parents of disobedient children express a strong sense of frustration. They believe the situation reflects not only the failure of their children but also their own life. L's father looked very pained during the interview. He saw himself as a visionary person, but also believed that he had been dedicated to his child's education. "I said everything I needed to say to her when she was a child," he claimed. He still did not understand why his daughter's life was so unsatisfactory. L's father described how he discouraged his daughter from moving to a school district and to not invest in a company, but his "stubborn" daughter always made him feel that his efforts and hardships were futile. He often thought that he "should not care about her anymore." The father wanted his daughter to live a safe and secure life. He helped her in the stock market, hoping she could become financially secure, but she was keen on "small investments for big returns" and investing in risky businesses. However, Ms. L did not consider her investments unwise. In her view, her father "cautioned and talked a lot" during her childhood, but she did not agree with all what he said. She said that after her first divorce, her parents strongly opposed her moving to a bigger place, but "in retrospect, it was fortunate that I bought this big apartment." In the case of conflicting relationships, the rational thinking of the offspring is inconsistent with the expectations of the parents, thus showing the characteristics of the power game and the emotional kidnapping.

Second, the nonstandard life path of the children's generation also damages the fulfillment of filial piety. In interviews, parents in cases 3 and 4 expressed anxiety about their children's marital status. In a community with close networks and clear pressure, children's marriage means the completion of parental duties. The maintenance of blood continuation is the need of self-social integrity (Yan 2012). However, under the situation of urban life, the pressure of public opinion felt by individuals is greatly reduced. Parents' strong expectation to have married children is mainly a kind of rational measure based on the reality of family welfare. As mentioned earlier, parents have deep anxiety regarding the idea that their children's lives will not be secure after their death, and marriage is an effective way to ensure that will happen. This provides a stronger sense of security than children's pursuit of fame and fortune. For parents who uphold the ethical concept of unlimited responsibility, they consider their children to be their lifelong responsibility unless their children have other effective supporting networks. Otherwise, they cannot let go and enjoy their old age. Therefore, parents with more limited resources have stronger demand for their children to have a more stable marriage. As L's mother expressed it, "If she has a complete home, her father and I can at least still take advantage of the time when we are still healthy and enjoy ten years of 
good time." If the children cannot understand the psychological state of the parents and do not try to reduce the pressure felt by parents, it will lead to parents complaining about "unfilial children" and "selfish children."

The interviews also show that due to the lack of consensus on a "good life," even if the offspring clearly express intentions to support their parents in the future, they still cannot successfully foster a sense of emotional achievement in the parents. In case 4, the daughter L said she decided to move to a larger apartment, not entirely for investment purposes but also to be able to live with her parents and child more comfortably. "In a few years, they will be even older. Living on their own is not possible. You always need someone by your side, right? By living with me I can still help." However, in the view of L's parents, there is too much friction with their daughter on a daily basis and living together is too hard. Their ideal is that the daughter can have a family of her own, and the old couple can escape from it and live in their own place.

The mother in case 3 repeatedly talked about the contradictions between her and her son's expectations for the future. She earnestly advised her son to give up the dream of fame in order to live a stable and ordinary happy life surrounded by children and grandchildren. However, in her son's view, this myopic vision came from the lack of money. Thus, he said that "when I become famous I will pay it all back to you." Y's mother said, "I know my son is still very filial; ... he will buy something for me on Mother's Day every year," but she suffered from her son not understanding her heart. Her question "Did I raise him just to let him pay me back?" indicates the pain she felt from her son not understanding her intentions. At the end of the interview, Y's mother explained her ideal life in a helpless tone, hoping her son would get married, have his own children, and live a stable life, so that her years of hard work were not wasted and she could feel that she had done her job. In the intergenerational relationship, the future of the family lies in the next generation. When the next generation is better off, it is a relief for the parents. In terms of realistic interests, for those who have limited financial capacity but can still care for themselves when they are old, the child's most important filial piety is not the promise to take care of the parents in the future but to become independent as early as possible in order to reduce parents' burden to save their pension.

In general, due to the lack of consistent expectations for the future, the offspring's ken lao cannot provide instrumental support for the parents, but also curtails independent pension resources in the future. Especially when the children deviate from the standard way of living, it destroys the basis for providing mental and emotional security for the parents. At a deeper level, children's obedience is the endogenous requirement of cultural traditions for intergenerational harmony (see Sun 2004). For parents who uphold the concept of parent-child unity and ethics of unlimited liability, their children's disobedience and nonstandard life paths are related not only to the loss of parents' authority but also the loss of future security.

\section{Conclusion and discussion}

As a type of ambivalent intergenerational relationship under the influence of the individualization process, ken lao reflects the strengths and inner tension of the parentchild culture in the Chinese family in the situation of social transformation. The strengths are indicated in ethics of intergenerational responsibility that still binds 
individuals in family life and is the basis of intergenerational instrumental solidarity. The tension is concentrated in the increasing difficulty of achieving solidarity of values. The realization of parents' authority is more and more dependent on the internalization of emotions in intergenerational interactions. The cases show that the harmonious ken lao family sustains the cultural tradition characterized by parent-child unity and infinite responsibility, and the interests, values, and emotions of the two generations are balanced. However, in traditional parental authority, the responsibility ethics and the family-centered relationship model are presented in the "modern" way of rational analysis and emotional orientation. The unbalanced ken lao family is an incomplete continuation of the cultural tradition of intergenerational harmony. The rebellion of the offspring regarding values and their instrumental reliance on their parents constitute the structural contradiction of the relationship. Due to the failure of the two generations' integration of values, the practice of responsibility ethics loses the foundation of reciprocity and balance, and the intergenerational relations fall into a rational conflict under the emotional kidnapping.

To sum up, this paper argues that the self-reflexivity of family intergenerational relations does not lead to individualization of the family in the process of individualization in China. On the contrary, parent-child unity and intergenerational responsibility ethics are negotiated and reproduced in the process of reflexivity. From the perspective of intergenerational relations, in contemporary China, the family is not only the resource for individuals to achieve self-interest but also a powerful structure that guiding and shaping the individual's expectation and behaviors. This situation does not fit the hypothesis in individualization theory that the family became a "selective relationship" (Beck and Beck-Gernsheim 2011, 110). Although the two generations show a high degree of rationalization and emotional orientation in the practice of intergenerational negotiation, the starting point and the result of reflection are relationship-oriented rather than individual-oriented. Whether the relationship is harmonious or conflicting, the parents and the offspring include each other's future in their own future life expectations. The cognition of young people's responsibility for their parents is the source of ken lao's legitimacy. The intergenerational responsibility based on blood is strongly shown to be nonselectable. In fact, it is this nonselectable bundle of relationships that produces intergenerational relationships of love and hate.

When understanding the intergenerational solidarity based on reflexivity in the present Chinese family, its structural characteristics and the role of interests, emotions, and values in the process of intergenerational solidarity involve the following points. First, the complementarity of the demand structure of parents and offspring is the basis of intergenerational cooperation. Because the elderly are financially self-sufficient and life expectancy and health conditions are greatly improved, they prolong their stage as a giver in support of their children. This increases the demand for emotional and mental support from their children (Kang 2012). In addition, the competition in the labor market is becoming increasingly intense, and young people's difficulty in becoming self-reliant has also increased. Due to the instability of marriage, lack of siblings, and insufficient social child care services and pension services, the parent-child relationship has become the most important tie and is often the only support network that individuals can rely on. As a result, the characteristics of the family as a community of needs have not diminished. In fact, even in the context of globalization and postmodernism with an increasingly diversified family structure, the family as a personal sanctuary is 
still the center of personal life. The family exists between the individual and the more macro structure, moderating the impact of globalization, community resources, and national policy on the individual. Individuals rarely make decisions independently from family resources and emotional dependencies. Therefore, the family as an agent is still a basic unit for social analysis.

Second, ken lao is a rational agreement between two generations, but the individual calculation is rationalized and accepted through emotions. In the context of Chinese family culture, filial piety is the main manifestation of the children's emotions toward the parents; the unequal relationship of intergenerational support can thus be balanced. The sense of achievement of self-sufficient urban parents is not based on the child's commitment to support them, but rather the emotional comfort and security brought by their children's "smooth life" and "obedience." However, in the context of authoritarian filial piety, the parents' authority cannot be derived from their identity as parents but from the child's life experience in the formation of emotional dependence on the parents and level of trust in the decision-making. The integration of values across generations is dependent on the daily interactions and emotional internalization when existing authority is lost. In the context of multivalues, the mutual, unconscious emotional reaction mode, and "collective inertia" formed in daily life between the two generations (Beck and Beck-Gernsheim, 2011: 7) can help achieve intergenerational understanding and successful negotiation.

Third, social transformation strengthens the emotional structure of parent-child unity, making intergenerational reciprocity present strong cultural resistance. Different from the emphasis on breaking away in an individualistic culture, China's intergenerational culture emphasizes the integration and coexistence of parents and children. Child rearing revolves around raising independent, complete individuals. The childish intimate interaction across generations is justified in China. China has experienced a series of antitraditional cultural movements since the beginning of the twentieth century, but the ideas of an independent self and separatism in intergenerational relations have not been institutionalized in the society (see also Sun 2004). The increased financial and marital risk in the social context of the parent-child relationship's instrumental solidarity has strengthened the meaning of interdependence and has become the most important resource for an individual to establish a sense of stability, security, and self-identity. It should be noted that in the only-child family, the uniqueness of the subject reduces the contradiction between intergenerational interests and also increases the urgency of intergenerational intimacy and intergenerational responsibility. This increases the risk of creating ambivalence. Also, because of the differences in resources among families, the high dependence of an individual on intergenerational bonds can lead to the intergenerational transmission of social inequality. This is a point that should not be overlooked when exploring the resilience of familism, intergenerational solidarity, and its consequences.

\section{Endnotes}

${ }^{1}$ The literal translation is "chewing the elderly."

${ }^{2}$ During the period of 2012-2014 the research group "Research on the Change in Family Intergenerational Cultural Values," which was chaired by the author, compiled a total of seventy-onecases in Shanghai through focus groups and in-depth interviews. The case of "ken lao" isonly a part of this collection. 


\section{Acknowledgements}

I would like to thank Dong Yingyi for contributing to the case study process and the anonymous reviewers for their pertinent and valuable advice.

This study is the procedural result of the 2011 National Social Science Fund Youth Project "Study on the change of intergenerational cultural values in contemporary families" (11CSH021). I would like to thank Dong Yingyi for contributing to the case study process and the anonymous reviewers for their pertinent and valuable advice.

\section{Funding}

This study was funded by the 2011 National Social Science Fund Youth Project "Study on the change of intergenerational cultural values in contemporary families" (11CSH021).

\section{Publisher's Note}

Springer Nature remains neutral with regard to jurisdictional claims in published maps and institutional affiliations.

Received: 9 May 2017 Accepted: 22 June 2017

Published online: 30 June 2017

\section{References}

Bawin-Legros, B, and JF Stassen. 2002. Intergenerational Solidarity: Between the Family and the State. Current Sociology 50(2): 243-262

Beck, U., and E. Beck-Gernsheim. 2011. Individualization (Chinese edition). Trans. R. Li, X. Fan, and H. Zhang. Beijing: Peking University Press

Bengtson, VL. 2001. Beyond the Nuclear Family: The Increasing Importance of Multigenerational Bonds. Journal of Marriage and Family 63(1): 1-16.

Bengtson, VL, and REL Roberts. 1991. Intergenerational Solidarity in Aging Families: An Example of Formal Theory Construction. Journal of Marriage and the Family 53(4): 856-870.

Burgess, EW, and HS Locke. 1945. The Family: From Institution to Companionship. New York: American Book Company. Chang, Kyung-Sup. 2010. Individualization without Individualism: Compressed Modernity and Obfuscated Family Crisis in East Asia. Journal of Intimate and Public Spheres 3: 23-39.

Che, M. 1990. The Counter-feedback Model of Intergenerational Relation in Chinese Families. Population Journal 4: 52-64.

Chen, H. 2012. A comparison of Kenlao between China and Western Countries. China Youth Study 3: 75-78.

Cherlin, AJ. 2008. Public and Private Families: An Introduction. New York: McGraw-Hill Humanities.

Cherlin, AJ. 2012. Goode's 'World Revolution and Family Patterns': A Reconsideration at Fifty Years. Population and Development Review 38(4): 577-607.

Connidis, IA. 2015. Exploring Ambivalence in Family Ties: Progress and Prospects. Journal of Marriage and Family 77(1): $77-95$.

Connidis, IA, and JA McMullin. 2002. Sociological Ambivalence and Family Ties: A Critical Perspective. Journal of Marriage and Family 64(3): 558-567.

Fei, W. 2009. The Sociological Research of 'NEET group' in China. Masters dissertation. Changchun, China: Northeast Normal University.

Fei, X. 1983. Support for the elderly in the changing family structure: A reconsideration of the dynamics of Chinese family structure. Journal of Peking University (Humanities and Social Sciences 3: 6-15.

Fei, W. 2002. Earthbound China and Procreation Institution. Beijing: Peking University Press.

Fingerman, KL, J Sechrist, and K Birditt. 2013. Changing Views on Intergenerational Ties. Gerontology 59(1): 64-70.

Gazso, A, and S McDaniel. 2015. Families by Choice and the Management of Low Income through Social Supports. Journal of Family Issues 36(3): 371-395.

Geng, Y. 2010. Depending on Elders in Countryside with Inner Logic_Based on the Investigation in Y village of He Nan Province. China Youth Study 12: 91-85.

Gilding, M. 2010. Reflexivity over and above Convention: The New Orthodoxy in the Sociology of Personal Life, Formerly Sociology of the Family. The British Journal of Sociology 61(4): 757-777.

He, X. 2009. Generation Relationship in Rural Households: As well as the Value Foundation of Generation Relationship. Social Science Research 5: 84-92.

Jiang, X. 2012. Inverse Intergenerational Relations: An Analysis on Hidden Ken Lao among Employed Urban Youth. China Youth Study 2: 21-25.

Kang, L. 2012. The change of the feedback model: Intergenerational relationships in transitional urban China. Shanghai: Shanghai Academy of Social Sciences.

Komter, AE, and WAM Vollebergh. 2002. Solidarity in Dutch Families: Family Ties Under Strain? Journal of Family Issues 23(2): 171-188.

Liang, S. 2010. The Fate of Chinese Culture. Beijing: China CITIC Press.

Liu, G. 2005. Why Are the Aged Suffering?--Analysis of Family Generation Relation Change. Journal of Nanchang University (Humanities and social Sciences) 36(6): 1-8.

Liu, W. 2012. Has filial piety declined? Attitudes, behavior and the influencing factors on supporting old parents. Youth Study 4: 22-32.

Liu, G. 2013. The Group Difference of Attitudes towards Intergenerational Support in Contemporary Families: Discussion on the Cultural Basis Changing of Feedback Model. Contemporary Youth Research 324(3): 5-12.

Ma, Z. 2008. Ken Lao Group: Anxiety Affects Thousands of Households. China Youth Study 2: 110-112.

Pan, G. 2000. Pan's collected works (Volume 1). Beijing: Peking University Press.

Pillemer, K, and JJ Suitor. 2002. Explaining Mothers' Ambivalence toward Their Children. Journal of Marriage and Family 64(3): 602-613. 
Potu. 2015. "Chinese-style ken lao, a kind of 'post-modern ken lao' in its essence". The website of 360 doc (http://www. 360doc.com/content/15/1008/17/3328689_504207663.shtml).

Shen, Yifei. 2013. iFamily: Individual, family and the state in the modernization of urban China. Shanghai: SDX Joint Publishing House.

Shi, Jinqun. 2014. Independence vs. Maintenance: the Ambivalence in the Family Intergenerational Relationship in Contemporary Urban Families. Journal of Guangxi University for Nationalities 36(4): 35-40.

Silverstein, M, D Gans, A Lowenstein, R Giarrusso, and VL Bengtson. 2010. Older Parent-Child Relationships in Six Developed Nations: Comparisons at the Intersection of Affection and Conflict. Journal of Marriage and the Family 72(4): 1006-1021.

Song, J, and J Qi. 2011. The NEETs in China: Detecting the Truth--An Empirical Analysis Based on Survey Data in 4 Cities. Population and Development 17(5): 57-64.

Spitze, G, and MP Gallant. 2004. The Bitter with the Sweet: Older Adults' Strategies for Handling Ambivalence in Relations with Their Adult Children. Research on Aging 26(4): 387-412.

Sun, L. 2004. The Deep Structure of Chinese Culture. Guilin: Guangxi Normal University Press.

Swartz, T. 2009. Intergenerational Family Relations in Adulthood: Patterns, Variations, and Implications in the Contemporary United States. Annual Review of Sociology 35: 191-212.

Tang, C, and W Chen. 2012. The Kinship of Urban Families in China: Based on the Survey of Family Structure and Kinship in Five Cities. Jiangsu Social Sciences 2: 92-103.

Wang, Y. 2014. Changing Lineal Families with Three Generations: An Analysis of the 2010 Census Data. Population Research 38(1): 51-62.

Xiao, S. 2014. 'Yan Mu Ci Zu': The Intergenerational Collaboration and Conflicts in Childrearing among Urban Families in Contemporary China. Sociological Studies 6: 148-171.

Hsu, F. L.K. 1990. Clan, Caste and Club. Trans. G. Xue and H. Shang. Beijing: Huaxia Publishing House

Xu, Q. 2013. The Influence of Children's Needs on Intergenerational Coresidence. Chinese Journal of Sociology 3: 111-130.

$\mathrm{Xu}, \mathrm{Q}$. 2011. A Survey on Intergenerational Communication in Rural Elder People's Families. Journal of Nanjing College for Population Programme Management 27(1): 5-10.

Yan, Y. 2006. Change in private life: Love, family and intimate relationships in a Chinese village (1949-1999). Trans. Gong, X. Shanghai: Shanghai Bookstore Publishing House

Yan, Y. 2011. "Contradictory Individual Images, Disputable Process of Individualization." In i China: The Rise of the Individual in Modern Chinese Society, eds. M. Halskov and R. Svarverud, trans. Y. Xu et al. Shanghai: Shanghai Translation Publishing Hous0065

Yan, Y.. 2012. The Individualization of Chinese Society. Trans. Y. Lu et al. Shanghai: Shanghai Translation Publishing House Yang, J, and Z He. 2014. Continuity or Change? Chinese Family in Transitional Era. Population Research 38(2): 36-51.

Yang, J, and L Li. 2009. Intergenerational Interaction and Family Cohesion--A Comparative Study of East Asian Countries and Regions. Sociological Studies 3: 26-53.

Yao, J. 2012. Temporary Stem Families: The Structural Change and Strategy of Urban Families. Youth Studies 3: 85-93.

Zhang, A. 2015. Emotional Strategy and Expectation of Family Relationships among Middle-Aged Rural Women: Practice among Women in Shang Cun, Hebei Province. Collection of Women's Studies 5: 19-28.

Zhang, J. 2008. Shang Hun and Ken Lao--the Cultural Logic of Rational Behaviors among the Generation born in 1980s. Youth Studies 6: 34-37.

Zhang, Q. 2010. The Sociological Study of the '80s NEET in Chinese Cities--Example of the '80s NEET in Hefei. Hefei, China: Masters dissertation Anhui University.

Zhou, Y. 2004. The Debates of Cultural Sociology: Conception, Relations and Reflection. Sociological Studies 5: 67-79.

Zhong, X, and S He. 2014. Negotiative Intimacy: Expectations of Family Relationship and Filial Piety among Only-child Parents. Open Times 1: 155-175.

Zhuang, L, and X Jian. 2013. Exploring the Rural Youth's 'NEET' Phenomena in Marriage at the Sight of Individualism: Take D Village of Heilongjiang Province for Example. Northwest Population Journal 3: 112-115.

\section{Submit your manuscript to a SpringerOpen ${ }^{\circ}$ journal and benefit from:}

- Convenient online submission

Rigorous peer review

Open access: articles freely available online

- High visibility within the field

- Retaining the copyright to your article 